\title{
Exploration of the safe water content and activity control points for medicinal and edible lotus seeds from mildew
}

\author{
Xiaofang Liao, Chaonan Sun, Fang Wei, Lidong Zhou* and Weijun Kong*
}

\begin{abstract}
Affected by the inner properties and the external environmental conditions, medicinal and edible lotus seeds are susceptible to mildew with fungal infection under suitable temperature and humidity conditions, leading to the production and contamination of various mycotoxins, along with threats to its quality and safety. In this study, the changes of water content $\left(C_{w}\right)$ and water activity $\left(A_{w}\right)$ of lotus seeds stored at $25^{\circ} \mathrm{C}$ and different relative humidity conditions, as well as the correlation between them and mildew of this edible and medicinal material were studied, aiming to explore the safe $C_{w}$ and $A_{w}$ control points for screening out the suitable storage conditions from mildew. Blank (without fungal conidia) and experimental (artificially added with Aspergillus flavus conidia) groups of lotus seeds were stored at $25^{\circ} \mathrm{C}$ and relative humidity of $40 \%, 50 \%, 60 \%$ and $70 \%$ for about 30 days, respectively. The mildew was observed and the changes of $C_{w^{\prime}} A_{w^{\prime}}$ together with the production of aflatoxins were measured. Results showed that no mildew was found and aflatoxins were not detected in lotus seeds when they were stored for 30 days at $25^{\circ} \mathrm{C}$ and relative humidity of $40 \%, 50 \%$ and $60 \%$ with $C_{w}<12 \%$ and $A_{w}<0.6$. While, when the relative humidity was up to $70 \%$, the $C_{w}$ and $A_{w}$ values rose quickly, and the $C_{w}$ exceeded the officially-permitted level (14\%). Although no mildew was observed, $A F B_{1}$ was still detected, increasing the potential risk of lotus seeds regarding aflatoxins. For warranting the quality with economic and safe storage, lotus seeds are suggested to be stored at $25^{\circ} \mathrm{C}$ and relative humidity lower than $60 \%$ with $12 \%$ and 0.6 as the safe $C_{w}$ and $A_{w}$ control points, respectively, to prevent medicinal and edible products from mildew and the contamination of aflatoxins.
\end{abstract}

Keywords: Lotus seeds, Mildew, Aflatoxins, Water content and activity, Relative humidity, Safe storage

\section{Introduction}

Foods including medicinal and edible products, feeds and medicinal plants are vulnerable to fungal conidia and mildew if improperly treated in the processes of growth, harvest, processing, storage and transportation (Giorni et al. 2018; Liu et al. 2015b; Zhang et al. 2019). Under suitable temperature $\left(20-35^{\circ} \mathrm{C}\right)$ and humidity (over $70 \%$ or water content more than $15 \%$ ) and sufficient nutrient conditions, these fungal conidia can sprout mycelium, secrete enzymes, and then dissolve foods or medicinal plants and decompose effective ingredients of them, reducing their

\footnotetext{
*Correspondence: Idzhou@implad.ac.cn; kongwj302@126.com Institute of Medicinal Plant Development, Chinese Academy of Medical Sciences \& Peking Union Medical College, Beijing 100193, China
}

quality and efficacy (Liu et al. 2015b). At the same time, some toxigenic fungi can produce secondary metabolites-mycotoxins with serious toxicity (Abarca et al. 2019; Dawit et al. 2019; Giorni et al. 2018; Jelena et al. 2019; Lv et al. 2019; Wang et al. 2009) to threaten their quality and safety, along with the physical and mental health of the consumers.

Various mycotoxins have been found with residue in different kinds of matrices (AlFaris et al. 2019; Kuang et al. 2013; Li et al. 2016; Liu et al. 2012; Su and Pan 2018; Wei et al. 2019; Xie and Li 2016). Among them, lotus seed (Nelumbo nucifera Gaertn), as a valuable and commonly-used edible and medicinal matrix, not only has the properties of tonifying spleen, stopping diarrhea, stopping bandage, tonifying kidney, nourishing heart and 
tranquilizing mind, but also is a common food or food additive with wide nutritional and edible functions. However, affected by the nature of their components and the external environmental conditions, lotus seeds are susceptible to mildew with fungal infection under suitable temperature and humidity conditions, especially during the plum rain season, leading to the production and residue of various mycotoxins, such as aflatoxins, ochratoxins, etc. Aflatoxins, mainly containing aflatoxin $\mathrm{B}_{1}$ $\left(\mathrm{AFB}_{1}\right), \mathrm{B}_{2}\left(\mathrm{AFB}_{2}\right), \mathrm{G}_{1}\left(\mathrm{AFG}_{1}\right)$, and $\mathrm{G}_{2}\left(\mathrm{AFG}_{2}\right)$ with strong hepatotoxicity and carcinogenic, teratogenic and mutagenic effects (Peckham et al. 1971), have been classified as Group 1A carcinogens by the International Agency for Research on Cancer (IARC) (World Health Organization [WHO] and International Agency for Research on Cancer [IARC] 1993). Liu et al. (2013) found that $95 \%$ $(19 / 20)$ lotus seeds samples were contaminated with aflatoxins at levels ranging from 0.02 to $6888.4 \mu \mathrm{g} / \mathrm{kg}$ and $\mathrm{AFB}_{1}$ was the predominant aflatoxin. Another study (Liu et al. 2019) regarding 57 lotus seed samples showed that $\mathrm{AFB}_{1}$ had the highest incidence of $26.3 \%$ with residual level from 0.25 to $7.48 \mu \mathrm{g} / \mathrm{kg}$. Similar results were also reported by Wei et al. (2019). Taking their prominent medicinal value and edible function, as well as the high occurrence of mildew and aflatoxins contamination into consideration, a maximum residue level (MRL) of $5 \mu \mathrm{g} / \mathrm{kg}$ for $\mathrm{AFB}_{1}$ and $10 \mu \mathrm{g} / \mathrm{kg}$ for the total amount of $\mathrm{AFB}_{1}+\mathrm{AFB}_{2}+\mathrm{AFG}_{1}+\mathrm{AFG}_{2}$ in lotus seeds (Chinese Pharmacopoeia Commission 2015a) have been officially set. Therefore, it is of great significance and urgency to prevent lotus seed from mildew and aflatoxins production through controlling the crucial factors or conditions, such as water content $\left(\mathrm{C}_{\mathrm{w}}\right)$, water activity $\left(\mathrm{A}_{\mathrm{w}}\right)$ and environmental temperature and humidity, to ensure their quality and safety.

It is generally believed that in the processing, storage and transportation processes, foods, medicinal plants and other matrices should be dried sufficiently to control their water content for inhibiting the growth of mildew or pests. In addition, $\mathrm{A}_{\mathrm{w}}$ (Rockland and Beuchat 1987) is also an important indicator that needs to be focused on and controlled by the dynamic measurement of water energy in foods, indicating the extent to which water can be used by microorganisms including toxigenic fungi. $\mathrm{A}_{\mathrm{w}}$ is expressed by the ratio of vapor pressure of water in the matrix to saturated vapor pressure of pure water, which is equal to the relative humidity of air above the sample. In addition, $A_{w}$ is directly related to the sensitivity of microorganisms in foods, and has a high correlation with the chemical and physical reactions of degradation on the shelf life of foods. And $\mathrm{A}_{\mathrm{w}}$ can be introduced to predict the longest shelf life (John et al. 2019), as well as to determine the packaging conditions and storage time of foods, etc. In some important regulations and guidance documents, $A_{w}$ has been the only factor that can be measured and quantified in the Hazard Analysis Critical Control Point (HACCP) system. In practice, foods are commonly dried to reduce the water content to prevent them from mildew. In the other hand, salt or sugar is added to decrease the $A_{w}$ of matrices to inhibit the growth of toxigenic fungi. Therefore, in public view, effective control $\mathrm{C}_{\mathrm{w}}$ and $\mathrm{A}_{\mathrm{w}}$ could prevent foods from mildew and the production of mycotoxins to ensure their safety.

Therefore, through the investigation of the $\mathrm{C}_{\mathrm{w}}$ and $\mathrm{A}_{\mathrm{w}}$ changes of lotus seeds under different storage conditions according to the experimental design in Fig. 1, we aimed to study the correlation of $\mathrm{C}_{\mathrm{w}}$ and $\mathrm{A}_{\mathrm{w}}$ and mildew for exploring the optimum water content and water activity control points for the safe storage. These findings will provide powerful supports and valuable references for screening for the reasonable, reliable and effective storage conditions to prevent medicinal and edible foods and other products from mildew and mycotoxins contamination for ensuring their quality and safety.

\section{Materials and methods Chemicals and reagents}

The mixed aflatoxins standard solution containing $2.0 \mathrm{mg} / \mathrm{mL}$ of $\mathrm{AFB}_{1}$ and $\mathrm{AFG}_{1}$, and $0.5 \mathrm{mg} / \mathrm{mL}$ of $\mathrm{AFB}_{2}$ and $\mathrm{AFG}_{2}$ was purchased from Pribolab Pte. Ltd. (Singapore). The ToxinFast ${ }^{\circledR}$-Aflatoxins Test immunoaffinity columns were bought from Huaan Magnech Bio-Tech Co., Ltd (Beijing, China). The aflatoxigenic Aspergillus flavus (A. flavus) lyophilized powder (CGMCC 3.4410) were got from the China General Microbiological Culture Collection Center (Beijing, China) and cultured to $1 \times 10^{7}$ conidia $/ \mathrm{mL}$ suspension for use.

HPLC-grade acetonitrile and methanol were obtained from Thermo Fisher Scientific Inc (Fair Lawn, NJ, USA). $\mathrm{NaCl}, \mathrm{KCl}, \mathrm{Na}_{2} \mathrm{HPO}_{4} \cdot 12 \mathrm{H}_{2} \mathrm{O}, \mathrm{NaH}_{2} \mathrm{PO}_{4}, \mathrm{KH}_{2} \mathrm{PO}_{4}$, and tween-20 were of analytical grade and purchased from Sinopharm Chemical Reagent Co., Ltd (Shanghai, China). Purified Wahaha water from Wahaha Group Co., Ltd (Hangzhou, China) was used for all the experiments.

\section{Sample collection and treatment}

Lotus seed (Nelumbo nucifera Gaertn.) samples, produced in Hubei province, (batch number 17050040, China) were purchased from Beijing Tong Ren Tang Co., LTD. All the samples were divided into the blank and experimental groups. For the blank groups: $20 \mathrm{~g}$ lotus seeds were added into 16 petri dishes, respectively, followed by irradiation for $5 \mathrm{~h}$ under an ultraviolet lamp. For the experimental groups: $20 \mathrm{~g}$ lotus seeds were added into another 16 petri dishes, respectively. After irradiation for $5 \mathrm{~h}, 1 \mathrm{~mL}$ of $A$. flavus conidia solution was 


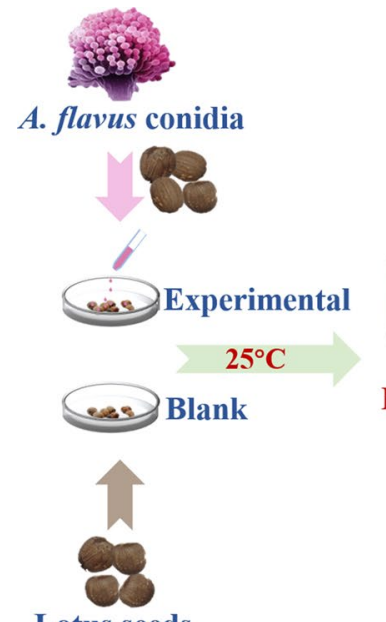

Lotus seeds

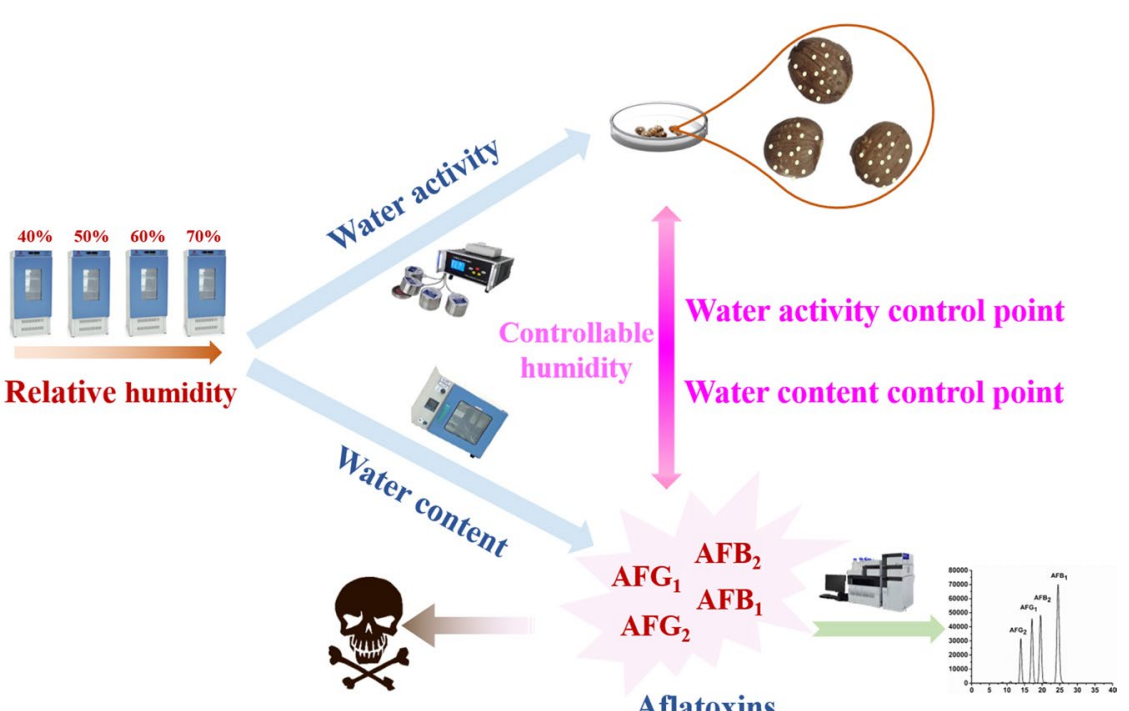

Fig. 1 Schematic diagram on exploration of the correlation between mildew and water content and activity of lotus seeds

artificially added onto the surface of lotus seeds and were air-dried. Then, all the petri dishes containing the raw and treated samples were stored in an incubator at $25{ }^{\circ} \mathrm{C}$ and relative humidity conditions of $40 \%, 50 \%, 60 \%$ and $70 \%$, respectively. On the 0,10 th, 20th and 30th day, all the samples were observed by naked eyes regarding mildew. In addition, the samples were treated for the measurement of $A_{w}$ and $C_{w}$, along with the determination of potential aflatoxins by the optimized high performance liquid chromatography coupled with photochemical derivatization and fluorescence detection (HPLC-PCD-FLD) method on the 0 , 3rd, 6th, 9th, 12th, 22nd and 32nd day.

\section{Water content determination}

The weight loss method recommended in the Chinese Pharmacopoeia (Chinese Pharmacopoeia Commission 2015b) was used. 2-5 g raw materials of lotus seed were accurately weighed and tiled in a flat weighing bottle with the thickness less than $5 \mathrm{~mm}$. After the samples were dried at $100-105^{\circ} \mathrm{C}$ for $5 \mathrm{~h}$ to constant weight, they were transferred to a dryer for cooling for $30 \mathrm{~min}$, followed by another drying at $100-105{ }^{\circ} \mathrm{C}$ for $1 \mathrm{~h}$ and cooling until the difference between the two successive weighing was not more than $5 \mathrm{mg}$. The water content $\left(\mathrm{C}_{\mathrm{w}}, \%\right)$ of sample was accurately calculated based on the lost weight.

\section{Water activity measurement}

Five gram lotus seeds out of the above samples stored at $25{ }^{\circ} \mathrm{C}$ and different relative humidity $(40 \%, 50 \%, 60 \%$ and $70 \%$ ) conditions were taken out on the 0 , 3rd, 6th, 9th, 12th, 22nd and 32nd day for the measurement of water activity $\left(\mathrm{A}_{\mathrm{w}}\right)$ by using a HD-6 (Wuxi Huake Instrument,
Wuxi, China) intelligent moisture activity measuring instrument. 15 min later, data of $\mathrm{A}_{\mathrm{w}}$ were recorded.

\section{Aflatoxins determination \\ Apparatus and high-performance liquid chromatography-fluorescence detection conditions}

Chromatographic separation of four aflatoxins was performed on a MG-III-C18 column $(4.6 \mathrm{~mm} \times 150 \mathrm{~mm}$, $5 \mu \mathrm{m}$ ) through a Shimadzu LC-20AT HPLC system (Shimadzu, Kyoto, Japan) consisting of two LC-20 AT pumps, an SIL-20A autosampler, a CTO-20A column oven, a CMB-20A controller, the post-column photochemical derivatization (PCD) reactor and an RF-20AXL fluorescence detector (FLD). Methanol-acetonitrile (40:18, $v / v)$ and water was selected as the mobile phase with isocratic elution at a flow rate of $1.2 \mathrm{~mL} / \mathrm{min}$. The column temperature was set at $30{ }^{\circ} \mathrm{C}$. The injection volume was $20 \mu \mathrm{L}$. The AURA INDUSTRIES PCD reactor (New York, NY, United States) was consisted of a mercury lamp $(\lambda=254 \mathrm{~nm})$ and a knitted reactor coil of $0.74 \mathrm{~mL}$ $(15 \mathrm{~m} \times 0.25 \mathrm{~mm})$. The eluate was monitored by using a fluorescence detector at an excitation wavelength of $360 \mathrm{~nm}$ and an emission wavelength of $450 \mathrm{~nm}$.

\section{Sample preparation for four aflatoxins determination}

Firstly, Phosphate buffer saline (PBS) solution was prepared by dissolving $0.2 \mathrm{~g} \mathrm{KCl}, 8.0 \mathrm{~g} \mathrm{NaCl}, 0.2 \mathrm{~g} \mathrm{KH}_{2} \mathrm{PO}_{4}$, $2.9 \mathrm{~g} \mathrm{Na}_{2} \mathrm{HPO}_{4} \cdot 12 \mathrm{H}_{2} \mathrm{O}$ in $1000 \mathrm{~mL}$ of purified water. 2\% PBT (phosphate buffer with addition of Tween-20) solution was obtained by dispersing $0.2599 \mathrm{~g} \mathrm{NaH}_{2} \mathrm{PO}_{4}$, $6.4204 \mathrm{~g} \mathrm{Na}_{2} \mathrm{HPO}_{4} \cdot 12 \mathrm{H}_{2} \mathrm{O}$ and $40 \mathrm{~mL}$ of tween- 20 in $1960 \mathrm{~mL}$ of purified water. 
Then, $5 \mathrm{~g}$ homogenized lotus seed sample powders that have been stored at $25{ }^{\circ} \mathrm{C}$ and relative humidity of $40 \%$, $50 \%, 60 \%$ and $70 \%$ for 30 days were accurately weighed and placed in a 50-mL centrifuge tube with the addition of $1 \mathrm{~g} \mathrm{NaCl}$ and $25 \mathrm{~mL}$ of methanol-water $(80: 20, v / v)$ solution. After blending by vortex and ultrasonication for $30 \mathrm{~min}$, the mixture was followed by centrifugation for $5 \mathrm{~min}$ at $10,000 \mathrm{r} / \mathrm{min}$ and $5 \mathrm{~mL}$ of the supernatant was collected and transferred into a 50-mL EP tube containing $40 \mathrm{~mL}$ of $1 \%$ PBT solution. The solution was mixed with $\mathrm{pH}$ being adjusted to $6-8$, followed by filtration through a $0.45-\mu \mathrm{m}$ syringe nylon filter. $40 \mathrm{~mL}$ of the filtrate was precisely measured and elutriated through an immunoaffinity column at a flow rate of $1-2 \operatorname{drop}(\mathrm{s})$ per second, then $10 \mathrm{~mL}$ of PBS and water were taken, respectively, to wash the column successively, and finally $800 \mu \mathrm{L}$ of methanol was added to elute the target aflatoxins. $1 \mathrm{~mL}$ of the eluent was collected and filtered through a 0.22 $\mu \mathrm{m}$ syringe nylon filter for HPLC-PCD-FLD analysis.

\section{Establishment of standard curves of four aflatoxins}

The mixed standard solution of aflatoxins was diluted to 9 different concentrations of working solutions, and $20 \mu \mathrm{L}$ of the dilution was injected successively from low concentration to high concentration into the HPLCPCD-FLD system. The peak area of each aflatoxin was recorded and the standard curve was established by linear regression of the peak area $(y)$ versus the injection concentration $(x)$. Then, the contents of aflatoxins in the tested samples were quantified according to the standard curves. All the working solutions were freshly prepared just before being injected into the HPLC analytical system.

\section{Statistical analysis}

All data regarding $\mathrm{C}_{\mathrm{w}}$ and $\mathrm{A}_{\mathrm{w}}$ were expressed as mean \pm standard deviation (SD) and analyzed by using the Origin 2016 software.

\section{Results}

\section{Changes of water content of lotus seeds during storage}

The $\mathrm{C}_{\mathrm{w}}$ of lotus seeds stored at $25{ }^{\circ} \mathrm{C}$ and different relative humidity conditions of $40 \%, 50 \%, 60 \%$ and $70 \%$ within 32 days was measured and shown in Fig. 2. It could be found that the $C_{w}$ values exhibited a fluctuation under different relative humidity conditions within the first 10 days, and then were relatively stable during the next 22 days, which was increased successively from low humidity to high humidity. The higher the relative humidity was, the bigger the $C_{w}$ value was. The samples stored at relative humidity $70 \%$ exhibited the highest $\mathrm{C}_{\mathrm{w}}$ values. After storage for 12 days at $25{ }^{\circ} \mathrm{C}$ and relative humidity $70 \%$, the $\mathrm{C}_{\mathrm{w}}$ value exceeded the prescribed limit

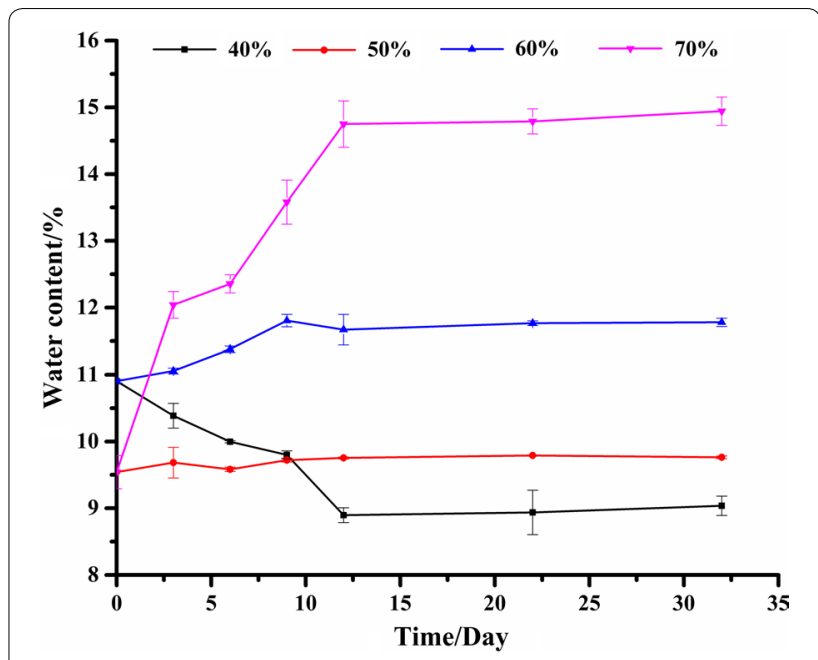

Fig. 2 Water content of lotus seeds stored at $25^{\circ} \mathrm{C}$ and different relative humidity conditions

(14\%) for lotus seeds in the Chinese Pharmacopoeia (Chinese Pharmacopoeia Commission 2015b). In addition, it could be found that when the relative humidity was lower than $70 \%$, the $C_{w}$ values were all not more than $12 \%$, which might be suggested as the suitable water content control point for safe storage of lotus seed in practice. These findings indicated that the relative humidity conditions for the storage environment of lotus seeds should be effectively controlled to lower the water content (not more than $12 \%$ ), and further to prevent this medicinal and edible food from mildew.

\section{Changes of water activity of lotus seed during storage}

The water activity $\left(\mathrm{A}_{\mathrm{w}}\right)$ data of lotus seeds stored at $25{ }^{\circ} \mathrm{C}$ and different relative humidity conditions of $40 \%, 50 \%$, $60 \%$ and $70 \%$ within 32 days were determined and listed in Fig. 3. It could be observed that the changes of $A_{w}$ values expressed a similar trend with $C_{w}$, which presented some fluctuation under different relative humidity conditions within the first 10 days, and then were stable during the next 22 days. After storage for 10 days at $25^{\circ} \mathrm{C}$, the $\mathrm{A}_{\mathrm{w}}$ values were increased with increasing the relative humidity from $40 \%$ to $70 \%$, which reached the highest values at relative humidity $70 \%$. After storage for 12 days at $25{ }^{\circ} \mathrm{C}$ and relative humidity $70 \%$, the $A_{w}$ values were bigger than 0.7 , which exceeded the relative humidity value of $70 \%$. When the relative humidity condition was lower than $70 \%$, the $A_{w}$ values were all smaller than 0.6, which might be considered as the suitable water activity control point for safe storage of lotus seed in practice. These data illustrate that the increase of relative humidity of storage condition will lead to the enhancement of the water activity of lotus seeds, which may raise the 


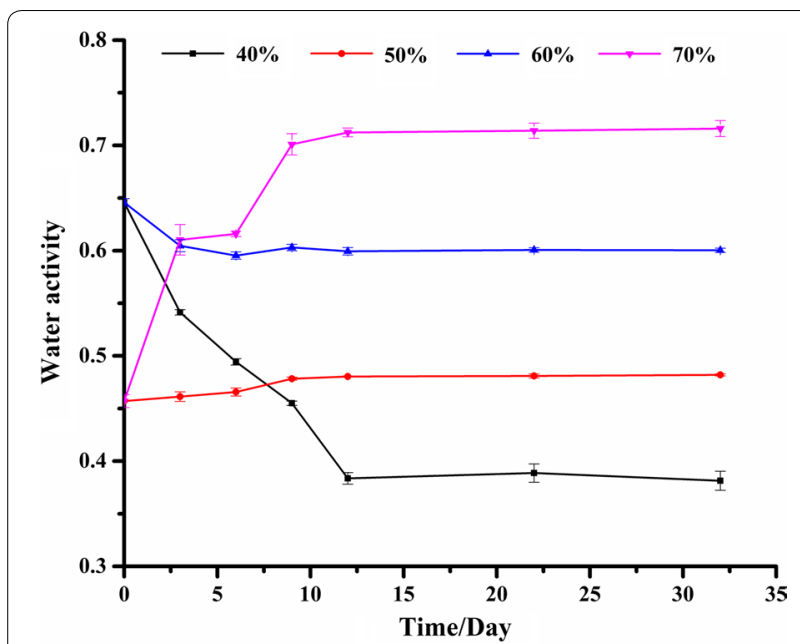

Fig. 3 Water activity of lotus seeds stored at $25^{\circ} \mathrm{C}$ and different relative humidity conditions (40\%, 50\%,60\% and $70 \%)$

incidence of mildew of this edible and medicinal food. While, from then on, the maximum limit standard, as well as some regulations on $A_{w}$ for lotus seed and other matrices are lacking. To prevent lotus seeds from mildew and mycotoxins contamination, it is suggested that the relative humidity conditions for the storage environment of lotus seed should be effectively controlled to lower the $A_{w}$ in an acceptable range (not more than 0.6).

\section{Mildew of lotus seed during storage}

The above results have shown that the $\mathrm{C}_{\mathrm{w}}$ and $\mathrm{A}_{\mathrm{w}}$ values were both increased with increasing the storage relative humidity from $40 \%$ to $70 \%$ at $25{ }^{\circ} \mathrm{C}$. Here, the mildew on the surface of blank lotus seeds (without fungal conidia) and experimental samples (inoculated with A. flavus conidia that could produce aflatoxins) stored at $25{ }^{\circ} \mathrm{C}$ and relative humidity $40 \%, 50 \%, 60 \%$ and $70 \%$ for 30 days was observed at an interval of 10 days. It could be seen in Fig. 4 that no visible mildew was found on the surface of all samples. Nevertheless, aflatoxins might be produced, which would be detected in the next part.

\section{Determination of aflatoxins \\ Standard curve of four aflatoxins}

Under the optimized chromatographic conditions, the HPLC-PCD-FLD chromatogram of four aflatoxins was recorded and shown in Fig. 5. Then, the peak area values $\left(y_{B 1}, y_{B 2}, y_{G 1}, y_{G 2}\right)$ of four aflatoxins at different concentrations $(x)$ were determined and the linear regression equations with their correlation coefficient $\left(R^{2}\right)$, as well as the limit of detection (LOD) and quantitation (LOQ) were obtained and listed in Table 1 . The results indicated that the developed HPLC-PCD-FLD method was sensitive and reliable for accurate quantitation of four aflatoxins in real samples within wide concentration ranges.

\section{Changes of aflatoxins contents in lotus seeds during storage}

Although no visible mildew was observed on the surface of lotus seeds by naked eyes within 30 days, it was not definite if toxic aflatoxins were produced in the samples. Herein, the lotus samples stored at $25{ }^{\circ} \mathrm{C}$ and relative humidity of $40 \%, 50 \%, 60 \%$ and $70 \%$ for $0,10,20$ and 30 days were collected and prepared for aflatoxins determination using the developed HPLC-PCD-FLD method.

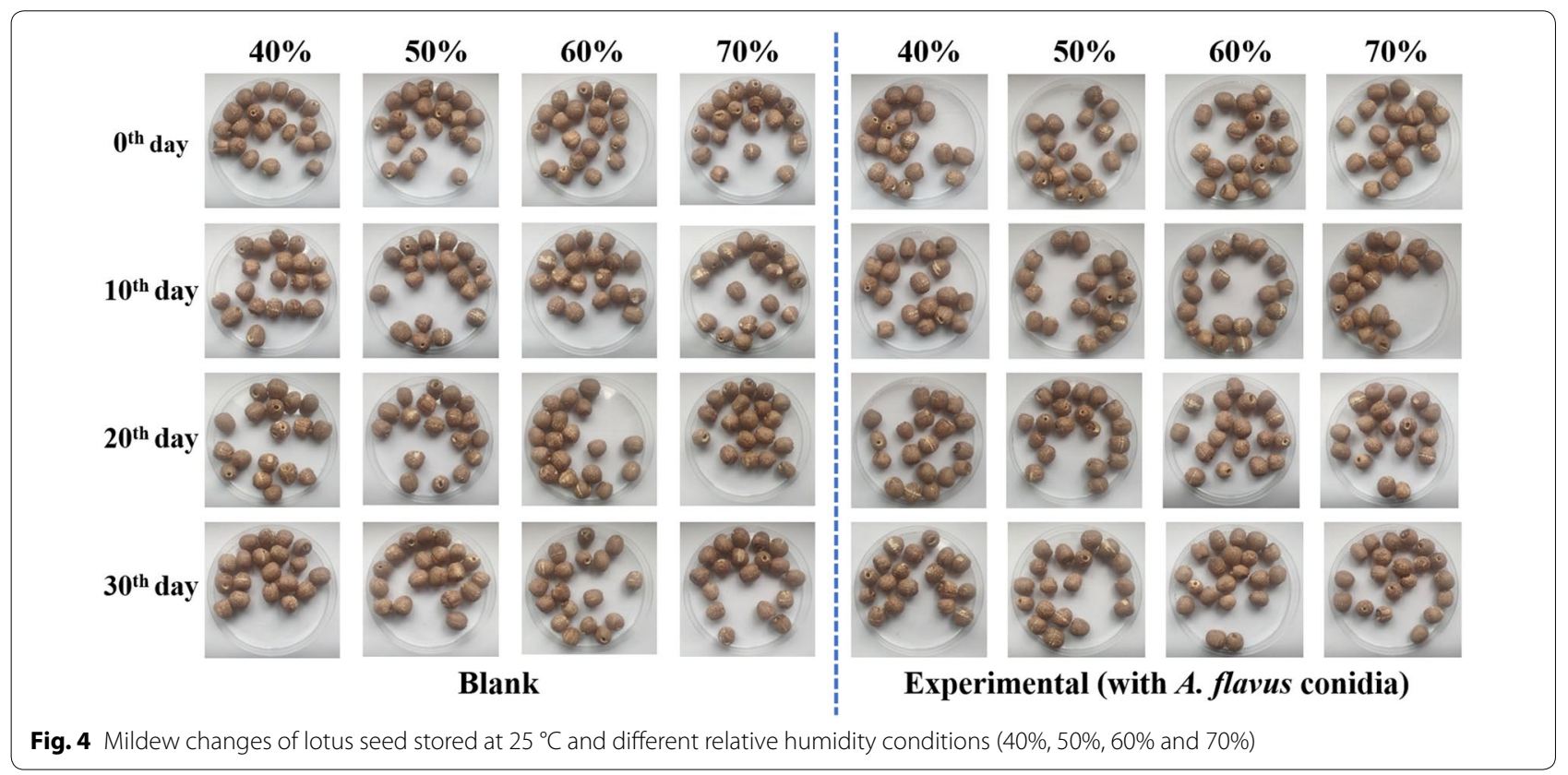




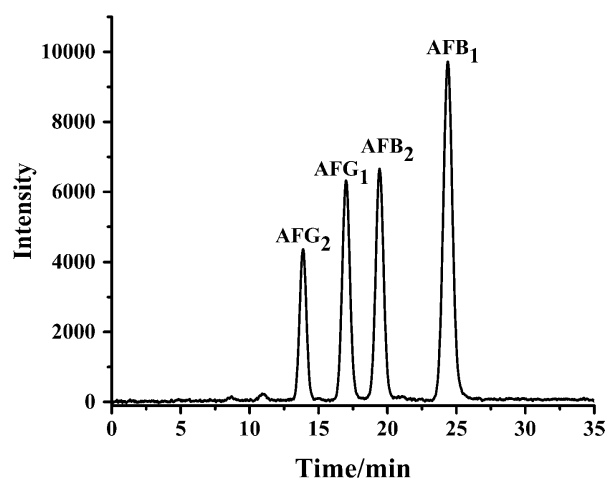

Fig. 5 HPLC-PCD-FLD chromatogram of four aflatoxins

The results in Table 2 showed that no aflatoxins were detected in lotus seed samples of both the blank and experimental groups when the relative humidity conditions were set at $40 \%, 50 \%$ and $60 \%$. While, when the relative humidity was up to $70 \%, \mathrm{AFB}_{1}$ was detected in both the blank and experimental lotus seed samples after they were stored at $25{ }^{\circ} \mathrm{C}$ for 30 days, and the concentration in the samples of experimental group reached $6.6 \mu \mathrm{g} / \mathrm{kg}$, which has exceeded the officially-recommended MRL $(5.0 \mu \mathrm{g} / \mathrm{kg})$.

These results indicated that lotus seed was a susceptible matrix to mildew and aflatoxins contamination. Although no visible mildew was observed, $\mathrm{AFB}_{1}$ could still be detected in lotus seeds stored for long time (about
30 days) at $25{ }^{\circ} \mathrm{C}$ and high relative humidity (around $70 \%$ ), especially in the samples without incubation with toxigenic fungi, which would increase the risk incidence of potential safety threatens of lotus seeds, and should be given more attention. Therefore, in practice, the relative humidity of storage environment for lotus seeds should be effectively controlled in less than $70 \%$ with the optimum water content and activity control points at $12 \%$ and 0.6 , respectively, for safe storage to ensure the quality and safety of this edible and medicinal food related products, as well as the health of consumers.

\section{Discussion}

Fungal spoilage and mycotoxin contamination are a major problem for many medicinal and edible foods and traditional Chinese medicines (TCMs). If storage conditions are poorly managed, some fungi species can infect these matrices, leading to mycotoxin contamination. Environmental temperature and humidity conditions are the two key factors for the growth of fungi, which should be in effective control to prevent foods, feeds and medicinal plants from mildew. In common, most fungi will grow and multiply quickly at $20-35{ }^{\circ} \mathrm{C}$ and relative humidity more than 70\% (Liu et al. 2015a, b). High environmental humidity will lead to the increase of $\mathrm{C}_{\mathrm{w}}$ and $A_{w}$ of the matrices for fungal growth, further may result in the occurrence of mildew and mycotoxins contamination (Abarca et al. 2019; Nian et al. 2018; Qiu et al. 2015; Wang et al. 2008; Xu et al. 2017; Yang et al. 2017; Zheng et al. 2016). Liu et al. (2015a) found that Areca catechu

Table 1 Regression equation, LOD and LOQ of four aflatoxins

\begin{tabular}{llllll}
\hline AFs & Regression equation & $\boldsymbol{R}^{2}$ & Linear range $(\mathbf{n g} / \mathbf{m L})$ & LOD $(\boldsymbol{\mu g} / \mathbf{k g})$ & LOQ $(\boldsymbol{\mu g} / \mathbf{k g})$ \\
\hline $\mathrm{AFB}_{1}$ & $y_{B 1}=33,420 x+49,526$ & 0.9999 & $0.78125-200.0$ & 0.30 & 0.88 \\
$\mathrm{AFB}_{2}$ & $y_{B 2}=76,477 x+30,833$ & 0.9999 & $0.39063-50.0$ & 0.15 & 0.44 \\
$\mathrm{AFG}_{1}$ & $y_{G 1}=17,988 x+26,881$ & 1.0000 & $0.78125-200.0$ & 0.30 & 0.88 \\
$\mathrm{AFG}_{2}$ & $y_{G 2}=43,679 x+19,772$ & 0.9998 & $0.39063-50.0$ & 0.15 & 0.44 \\
\hline
\end{tabular}

Table 2 AFs detected in lotus seeds during storage at $25^{\circ} \mathrm{C}$ and different relative humidity conditions

\begin{tabular}{|c|c|c|c|c|c|c|c|c|}
\hline \multicolumn{9}{|c|}{ Average levels of AFs at different storage time points $(\mu \mathrm{g} / \mathrm{kg}, n=3)$} \\
\hline \multirow{2}{*}{$\begin{array}{l}\text { Relative } \\
\text { humidity }\end{array}$} & \multicolumn{2}{|l|}{ Day 0} & \multicolumn{2}{|l|}{ Day 10} & \multicolumn{2}{|l|}{ Day 20} & \multicolumn{2}{|l|}{ Day 30} \\
\hline & Blank group & $\begin{array}{l}\text { Experimental } \\
\text { group }\end{array}$ & Blank group & $\begin{array}{l}\text { Experimental } \\
\text { group }\end{array}$ & Blank group & $\begin{array}{l}\text { Experimental } \\
\text { group }\end{array}$ & Blank group & Experimental group \\
\hline $40 \%$ & - & - & - & - & - & - & - & - \\
\hline $50 \%$ & - & - & - & - & - & - & - & - \\
\hline $60 \%$ & - & - & - & - & - & - & - & - \\
\hline $70 \%$ & - & - & - & - & - & - & $<\mathrm{LOQ}\left(\mathrm{AFB}_{1}\right)$ & $6.6^{\mathrm{a}}\left(\mathrm{AFB}_{1}\right)$ \\
\hline
\end{tabular}

a $\mathrm{RSD}<0.2 \%$ 
was not susceptible to mildew infection or mycotoxins production in the environment with humidity below $90 \%$ and temperature under $25{ }^{\circ} \mathrm{C}$. The best storage conditions for Radix Astragali and Alpinia oxyphylla to avoid Aspergillus flavus contamination were temperature and humidity below $25{ }^{\circ} \mathrm{C}$ and $85 \%$, respectively ( $\mathrm{Hu}$ et al. 2015; Zhao et al. 2017).

Lotus seeds contain approximately $500 \mathrm{~g} / \mathrm{kg}$ (dry basis) starch (Zhang et al. 2014; Wang et al. 2018; Lei et al. 2020), as well as up to $19.85 \%$ protein (Zeng et al. 2013), which provide a large amount of nutrients for the growth and reproduction of fungi like Aspergillus flavus, under suitable experimental conditions. Therefore, it is of great significance to study the critical conditions for lotus seeds to mildew and infect aflatoxins. In this study, the blank (untreated samples) and experimental (artificially-contaminated samples with aflatoxigenic A. flavus conidia) samples of lotus seeds were stored at $25{ }^{\circ} \mathrm{C}$ and different relative humidity conditions to measure the $C_{w}$ and $A_{w}$ changes. Our results have shown that both the $\mathrm{C}_{\mathrm{w}}$ and $\mathrm{A}_{\mathrm{w}}$ values tended to be stable after storage for 10 days, and no obvious mildew was observed on the surface of all tested samples for 30 days. When the relative humidity was up to $70 \%$, the $\mathrm{C}_{\mathrm{w}}$ and $\mathrm{A}_{\mathrm{w}}$ values were increased quickly, and the $C_{w}$ value exceeded the official-permitted level (14\%), which was in agreement with the reports (Liu et al. 2015b). Within 30 days, although mildew was not observed, $\mathrm{AFB}_{1}$ could still be detected, which would increase the potential risk of lotus seeds regarding aflatoxins.

In the practical medicinal and edible foods and TCMs storage process, the experimental temperature and humidity, as well as the $C_{w}$ and $A_{w}$ conditions were seldom paid special attention and failed to control. Changes of weather and environmental conditions will lead to large humidity fluctuations. When the environmental humidity is above $70 \%$ for a long time, the water content and activity of foods will be high, which will easily result in the mildew of TCMs, along with mycotoxins contamination. Our results have exhibited that when the relative humidity was no more than $60 \%$, the $\mathrm{C}_{\mathrm{w}}$ and $\mathrm{A}_{\mathrm{w}}$ values approximately equal to about $12 \%$ and 0.6 , respectively, which might be recommended as the optimum water content and water activity control points for safe storage of lotus seeds in practice at $25{ }^{\circ} \mathrm{C}$ with the environmental relative humidity less than $60 \%$, to ensure the quality, safety and effectiveness of medicinal and edible products, as well as the health of the consumers.

\section{Acknowledgements}

Not applicable.

\section{Authors' contributions}

XFL carried out the experimental studies, participated in the experiments and drafted the manuscript. CNS carried out the analysis. FW and participated in the design of the study and performed the statistical analysis. LDZ and WJK conceived of the study, and participated in its design and coordination and helped to draft the manuscript. All authors read and approved the final manuscript.

\section{Funding}

The authors are grateful for the support from the National Natural Science Foundation of China (81673593 and 81973474), CAMS Innovation Fund for Medical Sciences (2016-I2M-3-010) and CAMS 2018 Young Talent Program (2018RC350020).

\section{Availability of data and materials}

All data in this manuscript were deposited in publicly available repositories in the Institute of Medicinal Plant Development, Chinese Academy of Medical

Sciences \& Peking Union Medical College, Beijing, China.

\section{Ethics approval and consent to participate}

Not applicable.

\section{Consent for publication}

All authors agree with the publication in this journal.

\section{Competing interests}

The authors declare that they have no competing interests.

Received: 16 January 2020 Accepted: 25 April 2020

Published online: 12 May 2020

\section{References}

Abarca ML, Bragulat MR, Castellá G, Cabañes FJ (2019) Impact of some environmental factors on growth and ochratoxin a production by Aspergillus niger and Aspergillus welwitschiae. Int J Food Microbiol 291:10-16

AlFaris NA, ALTamimi JZ, ALOthman ZA, Al Qahtani SF, Wabaidur SM, Ghfar AA, Aldayel TS (2019) Analysis of aflatoxins in foods retailed in Saudi Arabia using immunoaffinity column cleanup and high-performance liquid chromatography-fluorescence detection. J King Saud Univ Sci. https:// doi.org/10.1016/j.jksus.2019.11.039

Chinese Pharmacopoeia Commission (2015a) Pharmacopoeia of the People's Republic of China, vol I, 2015th edn. China Med Sci Press, Beijing, p 273

Chinese Pharmacopoeia Commission (2015b) Pharmacopoeia of the People's Republic of China, vol IV, 2015th edn. China Med Sci Press, Beijing, p 104

Dawit G, Chih-Hsuan C, Barbara S, Sandra DLT, Wei-tsyi ET (2019) Aflatoxin $\mathrm{B}_{1}\left(\mathrm{AFB}_{1}\right)$ production by Aspergillus flavus and Aspergillus parasiticus on ground Nyjer seeds: the effect of water activity and temperature. Int J Food Microbiol 296:8-13

Giorni P, Pietri A, Bertuzzi T, Soldano M, Piccinini S, Rossi L, Battilani P (2018) Fate of mycotoxins and related fungi in the anaerobic digestion process. Bioresour Technol 265:554-557

Hu YC, Kong WJ, Liu QT, Zhao G, Yang MH (2015) Study on the influence of Aspergillus flavus on the quality of Radix astragali and its storage conditions optimization. Mod Chin Med 17:1133-1138

Jelena K, Siniša M, Aleksandra B, Lato P, Jovana K, Nataša Ć (2019) The effect of storage temperature and water activity on aflatoxin $B_{1}$ accumulation in hull-less and hulled spelt grains. J Sci Food Agric 99:3703-3710

John JM, Jinap S, Hanani ZAN, Nor-Khaizura MAR, Samsudin NIP (2019) The effects of different packaging materials, temperatures and water activities to control aflatoxin $\mathrm{B}_{1}$ production by Aspergillus flavus and A. parasiticus in stored peanuts. Int J Food Sci Technol 56:3145-3150

Kuang Y, Qiu F, Kong WJ, Luo JY, Cheng HY, Yang MH (2013) Simultaneous quantification of mycotoxins and pesticide residues in ginseng with one-step extraction using ultra-high performance liquid chromatography-electrospray ionization tandem mass spectrometry. J Chromatogr B 939:98-107

Lei SZ, Li X, Liu L, Zheng MJ, Chang Q, Zhang Y, Zeng HL (2020) Effect of lotus seed resistant starch on tolerance of mice fecal microbiota to bile salt. Int J Biol Macromol 151:384-393

Li MH, Kong WJ, Li YJ, Liu HM, Liu QT, Dou XW, Ou-yang Z, Yang MH (2016) High-throughput determination of multi-mycotoxins in Chinese yam and related products by ultra fast liquid chromatography coupled with 
tandem mass spectrometry after one-step extraction. J Chromatogr B 1022:118-125

Liu SY, Qiu F, Yang MH (2012) Determination of aflatoxins in Nelumbinis Semen by immunoaffinity column clean-up and HPLC-FLD with on-line postcolumn photochemical derivatization and LC-MS/MS confirmation. China J Chin Mater Med 37:305-309

Liu SY, Qiu F, Kong WJ, Wei JH, Xiao XH, Yang MH (2013) Development and validation of an accurate and rapid LC-ESI-MS/MS method for the simultaneous quantification of aflatoxin $B_{1}, B_{2}, G_{1}$ and $G_{2}$ in lotus seeds. Food Control 29:156-161

Liu HM, Kong WJ, Hu YC, Yang MH (2015a) Application of response surface analysis in the investigation of storage condition of Areca catechu. World Chin Med 10:1129-1132

Liu QT, Kong WJ, Yang MH, Guo WY (2015b) Review of scientific preservation techniques for traditional Chinese medicine becoming mouldy during storage. China J Chin Mater Med 40:1223-1229

Liu XF, Ying GY, Liao XF, Sun CN, Wei F, Xing XY, Shi LC, Sun YF, Kong WJ, Zhou LD (2019) Cytometric microbead magnetic suspension array for high-throughput ultrasensitive detection of aflatoxin $\mathrm{B}_{1}$. Anal Chem 91:1194-1202

Lv C, Jin J, Wang P, Dai XF, Liu Y, Zheng MM (2019) Interaction of water activity and temperature on the growth, gene expression and aflatoxin production by Aspergillus flavus on paddy and polished rice. Food Chem 293:472-478

Nian YJ, Wang HW, Ying GY, Yang MH, Wang Z, Kong WJ, Yang SH (2018) Transfer rates of aflatoxins from herbal medicines to decoctions determined by an optimized high-performance liquid chromatography with fluorescence detection method. J Pharm Pharmacol 70:278-288

Peckham JC, Doupnik B, Jones OH (1971) Acute toxicity of ochratoxins A and B in chicks. Appl Microbiol 21:492-494

Qiu GY, Peng GL, Wu SF, Luo CW, Yang L (2015) Adsorption isotherms and thermodynamic properties of Zanthoxylum bungeanum seeds. Food Sci $36: 1-5$

Rockland LB, Beuchat LR (1987) Water activity: theory and applications to food. Marcel Dekker Inc, New York

Su XJ, Pan XM (2018) Determination of aflatoxins in hawthorn by high performance liquid chromatography after immunoaffinity column clean-up and post-column derivatization. Contemp Med Symp 16:189-190

Wang C, Zhang X, Dai KZ, Wu GX (2008) Selection of fitting models on adsorption and desorption isotherms of chrysanthemum. J Yangtze Univ 5(24-26):38

Wang CH, Zhang BS, Meng QK (2009) Research progress on the harm of common fungal toxins to human body and biodegradation. Shanxi J Agric Sci 55:99-101
Wang Q, Zheng YF, Zhuang WJ, Lu X, Luo XL (2018) Genome-wide transcriptional changes in type 2 diabetic mice supplemented with lotus seed resistant starch. Food Chem 264:427-434

Wei F, Liu XF, Liao XF, Shi LC, Zhang SW, Lu JH, Zhou LD, Kong WJ (2019) Simultaneous determination of 19 mycotoxins in lotus seed using a multimycotoxin UFLC-MS/MS method. J Pharm Pharmacol 71:1172-1183

World Health Organization [WHO] and International Agency for Research on Cancer [IARC] (1993) Some Naturally Occurring Substances: Food Items and Constituents, Heterocyclic Aromatic Amines and Mycotoxins. IARC Monogr. Eval. Carcinog. World Health Organization, Geneva, p 56

Xie X, Li HY (2016) Determination of aflatoxins in platycladi seeds by HPLC combined with immunoaffinity column cleanup and post-column photochemical derivatization. Chin J PTCA. 52:541-544

Xu Y, He Y, Zhang AL, Zhang Y, Rao XY, Luo XJ (2017) Study on moisture absorption characteristics of honeysuckle spray powder by dynamic vapour sorption method. Chin Tradit Herbal Drugs 48:3353-3358

Yang ZX, Wang HW, Ying GY, Yang MH, Nian YJ, Liu JJ, Kong WJ (2017) Relationship of mycotoxins accumulation and bioactive components variation in ginger after fungal inoculation. Front Pharmacol 8:331

Zeng HY, Cai HL, Cai XL, Wang YJ, Li YQ (2013) Amino acid profiles and quality from lotus seed proteins. J Sci Food Agric 93:1070-1075

Zhang Y, Zeng HL, Wang Y, Zeng SX, Zheng BD (2014) Structural characteristics and crystalline properties of lotus seed resistant starch and its prebiotic effects. Food Chem 155:311-318

Zhang L, Zhou XK, Gu QC, Liang MZ, Mu SL, Zhou B, Huang F, Lin B, Zou CX (2019) Analysis of the correlation between bacteria and fungi in sugarcane tops silage prior to and after aerobic exposure. Bioresour Technol 291:121835

Zhao XS, Wei JH, Zhou YK, Kong WJ, Yang MH (2017) Quality evaluation of Alpinia oxyphylla after Aspergillus flavus infection for storage conditions optimization. AMB Expr 7:151

Zheng L, He Y, Zhang JH, Wang WK, Li X, Rao XY (2016) Isothermal adsorption, desorptionand thermodynamic properties of Scutellaria baicalensis pieces. China J Chin Mater Med 41:830-837

\section{Publisher's Note}

Springer Nature remains neutral with regard to jurisdictional claims in published maps and institutional affiliations.

\section{Submit your manuscript to a SpringerOpen ${ }^{\circ}$ journal and benefit from:}

- Convenient online submission

- Rigorous peer review

- Open access: articles freely available online

- High visibility within the field

- Retaining the copyright to your article

Submit your next manuscript at $\boldsymbol{\nabla}$ springeropen.com 